\title{
A importância da música na aprendizagem de uma criança com deficiência múltipla
}

\author{
The importance of music in the learning of a child with multiple disabilities \\ La importancia de la música en el aprendizaje de un niño con múltiples discapacidades
}

Recebido: 25/08/2021 | Revisado: 03/09/2021 | Aceito: 07/09/2021 | Publicado: 09/09/2021

\author{
Izabel Cristina Lopes de Almeida \\ ORCID: https://orcid.org/0000-0001-5679-184X \\ Secretaria da Educação do Estado do Ceará, Brasil \\ E-mail: izabelmatheus@gmail.com \\ Ana Raquel Lopes Soares de Almeida \\ ORCID: https://orcid.org/0000-0002-9151-6736 \\ Universidade Estadual do Ceará, Brasil \\ E-mail: anaraquell45almeida@gmail.com \\ Vera Lúcia Pontes Juvêncio \\ ORCID: https://orcid.org/0000-0002-4912-0770 \\ Universidade Federal do Ceará, Brasil \\ E-mail: verajuv@gmail.com
}

\begin{abstract}
Resumo
O trabalho objetivou investigar a importância da música na aprendizagem de uma criança com deficiência múltipla, buscando identificar as aquisições no vocabulário, verificar a interação com outras pessoas no ambiente escolar e certificar a repercussão no contexto familiar. Configura um estudo de caso, desenvolvido em uma instituição de educação para pessoas com deficiência visual, de acordo com as observações da dificuldade de comunicação e interação de uma aluna com deficiência múltipla (Síndrome de Down, Transtorno do espectro autista-TEA e deficiência visual baixa visão) adveio este estudo. A metodologia associou aulas práticas de música à luz da visão interacionista, com apoio nas cantigas populares e do cotidiano da criança, em que foram realizados exercícios de respiração e relaxamento, atividades envolvendo a exploração dos sons do corpo, a manipulação de instrumentos de bandinha, a coordenação do movimento rítmico com a expressão verbal seguindo uma sequência, a execução de andamento, a imitação e as variações de velocidade. Em diálogo com autores da pedagogia e educação musical foi percebido a música como um excelente facilitador na aprendizagem da aluna, foram adicionadas novas palavras ao vocabulário, relacionadas as cantigas aprendidas, também favoreceu a inclusão social e, contribuiu, para uma melhora significativa na capacidade de expressão, relacionamento, ampliação do senso de superação e elevação da autoestima. Infere-se, portanto, que a música é um excelente meio de contribuir com o desenvolvimento de todos os indivíduos, no contexto da educação de participantes com deficiência, impõem-se a adoção de metodologias específicas visando ao atendimento às demandas individuais.
\end{abstract}

Palavras-chave: Musicalização; Comunicação; Interação.

\begin{abstract}
The study aimed to investigate the importance of music in the learning of a child with multiple disabilities, seeking to identify vocabulary acquisitions, verifying the interaction with other people in the school environment and certifying the repercussions in the family context. It sets up a case study, developed in an educational institution for people with visual impairment, according to the observations of communication and interaction difficulties of a student with multiple disabilities (Down Syndrome, ASD-Autistic Spectrum Disorder and low visual impairment vision) came from this study. The methodology associated practical music classes in the light of the interactionist view, with support in popular songs and the child's daily life, in which breathing and relaxation exercises were performed, activities involving the exploration of body sounds, the manipulation of band instruments, the coordination of rhythmic movement with verbal expression following a sequence, the execution of tempo, imitation and variations in speed. In dialogue with authors of pedagogy and music education, music was perceived as an excellent facilitator in the student's learning, new words were added to the vocabulary, related to the songs learned, it also favored social inclusion and contributed to a significant improvement in the ability to expression, relationship, expansion of the sense of overcoming and raising self-esteem. It is inferred, therefore, that music is an excellent means of contributing to the development of all individuals, in the context of educating participants with disabilities, it is necessary to adopt specific methodologies aimed at meeting individual demands.
\end{abstract}

Keywords: Musicalization; Communication; Interaction. 


\begin{abstract}
Resumen
El estudio tuvo como objetivo investigar la importancia de la música en el aprendizaje de un niño con discapacidad múltiple, buscando identificar adquisiciones de vocabulario, verificando a las otras personas en el entorno escolar y certificando las repercusiones en el contexto familiar. Se configura un caso de estudio, desarrollado en una institución educativa para personas con discapacidad visual, de acuerdo con las observaciones de las dificultades de comunicación e interacción de un estudiante con discapacidad múltiple (Síndrome de Down, TEA-Trastorno del espectro autista y baja discapacidad visual) proveniente de este estudio. La metodología asoció clases prácticas de música a la luz de la mirada interaccionista, con apoyo en canciones populares y la vida cotidiana del niño, en las que se realizaron ejercicios de respiración y relajación, actividades de exploración de sonidos corporales, manipulación de instrumentos de banda, coordinación de movimiento rítmico con expresión verbal siguiendo una secuencia, ejecución de tempo, imitación y variaciones de velocidad. En diálogo con autores de pedagogía y educación musical, la música se percibió como un excelente facilitador en el aprendizaje del alumno, se agregaron nuevas palabras al vocabulario, relacionadas con las canciones aprendidas, también favoreció la inclusión social y contribuyó a una mejora significativa en la capacidad. a la expresión, expansión del sentido de relación y elevación de la autoestima. Se infiere, por tanto, que la música es un excelente medio para contribuir al desarrollo de todas las personas, en el contexto de la educación de los participantes con discapacidad, es necesario adoptar procedimientos específicos dirigidos a satisfacer las demandas individuales.
\end{abstract}

Palabras clave: Musicalización; Comunicación; Interacción.

\title{
1. Introdução
}

A pessoa com deficiência múltipla (DM) é aquela com uma condição complexa que revela associações de duas ou mais incapacidades, que prejudicam o seu desenvolvimento individual e o relacionamento com o outro (Felício, Gomes, Rodrigues, 2019; Bosco, Mesquita \& Maia, 2010). Segundo Junior, Moreira (2021) e Godói (2006), o deficiente múltiplo apresenta alteração de ordem física, sensorial, mental, emocional ou de comportamento social, no entanto, não é a quantidade das inaptidões que irá determinar se a pessoa tem ou não DM, mas a gravidade de seu transtorno. Neste contexto, torna-se indispensável na educação das pessoas que apresentam essas alterações acentuadas, adaptar métodos e técnicas de ensino para desenvolver sua capacidade de comunicação, expressão e interação na comunidade com diversos indivíduos e propiciar sua autonomia e independência.

Na compreensão de Oliveira (1997) e Ivic (2010) o desenvolvimento do aluno ocorre por meio da interação social, com outras pessoas e com o ambiente onde convivem, sendo assim, acontece em entrosamento com as pessoas da escola e no âmbito escolar, esse conjunto de estímulos enseja a geração de mais experiências e conhecimento. A aprendizagem, portanto, resulta da experiência social, mediada pela utilização de elementos e artefatos de comunicação e signos, com a constituição dos conceitos utilizados pelo próprio envolvido, o agente-partícipe (Lima, 2014), tal se coaduna ao pensamento de Vygotsky, quando ele ensina que, para o desenvolvimento humano é importante a apropriação das experiências em sua cultura, bem como das ações, linguagens e processos interativos.

Segundo Brandão (2011) a interação social deve ocorrer no âmbito da Zona de Desenvolvimento Proximal (ZDP), em conformidade com Vygotsky, pois esta conforma o estado ou a distância entre aquilo que a pessoa já sabe, seu conhecimento real, e aquilo que o sujeito possui potencialidade para aprender, seu conhecimento potencial. É necessário reconhecer as diferenças entre os alunos e, além disso, valorizar as características de cada um, favorecendo a aprendizagem.

O trabalho com crianças com DM é proposto por Godói (2006), utilizando as linguagens, artes visuais e plásticas, música, dança, teatro, movimento e literatura integrada ao ensino, neste contexto, é importante destacar a música como uma linguagem que possibilita o desenvolvimento de novas capacidades (Deckert, 2012). Em consonância com o terceiro volume do Referencial Curricular Nacional para a Educação Infantil “[...] o trabalho com a música é um meio de expressão e forma de conhecimento acessível aos bebês e crianças, inclusive para aquelas que apresentem necessidades especiais" (Brasil, 1998, p. 47). Em atividades em grupo, também é excelente para desenvolver a socialização, a autoestima e o autoconhecimento, pois a criança ao participar vai descobrindo e desenvolvendo potencialidades, além da vantagem de interagir com o outro. Por ser oportuno, reforça-se a noção de que as atividades musicais devem ter significação para o aluno, precisando levando em 
consideração as necessidades e condições do educando, assim como os seus interesses musicais (Souza, 2009).

A partir do século XX a música passou por mudanças e transformações com a divulgação de vários métodos de ensino propostos por músicos-pedagogos, a fim de ampliar a prática pedagógica. Alguns destes foram importados da Europa, segundo Penna (2011) contribuíram e ainda contribuem para "[...] renovar o ensino de música, a questionar os modelos tradicionais e conservadores, procurando ampliar o alcance da educação musical ao defender a ideia de que a música pode ser ensinada a todos, e não apenas aqueles supostamente dotados de um dom inato" (Penna, 2011, p. 17). De início, conforme Almeida (2003), os Métodos Tradicionais priorizavam a formação técnica do músico instrumentista, dos cantores, compositores e regentes, salienta-se que os seguidores desta escola defendiam o ensino somente para pessoas com talento musical. Em seguida, com os Métodos Alternativos admitiu-se uma possibilidade de Educação Musical diferenciada aplicada a todas as pessoas, onde o professor era um mediador, considerando as potencialidades do indivíduo e o seu processo de aprender.

Com a institucionalização da Lei 11.769, o ensino da música passou a ser compulsório (Brasil, 2008, Barros, Tavares \& Marques, 2018) na educação básica. Essa arte mostra-se como uma área de conhecimento com diversas funções e várias abordagens, fato representativo de um grande avanço, tornando-a acessível a todos os alunos indistintamente (Brasil, 2015), no entanto cabe aos professores saber como elaborar e aplicar as atividades e sessões musicais de maneira a torná-las acessíveis. Educação Musical, feita conteúdo curricular, é estudada segundo Deckert (2012), com suporte nos seus elementos o ritmo, a melodia, a harmonia, e o andamento. Por meio desta, a criança adquire conhecimento interagindo com a linguagem musical e seus componentes, através de atividades que proporcionam manipulação direta com estes chegando à apreciação, criação e execução musical.

Na compreensão de Barros, Tavares e Marques (2018) a promoção de “[...] atividades que envolvam a musicalidade na Educação Infantil pode ser uma ferramenta eficaz na promoção do desenvolvimento, favorecendo diversos aspectos, tais como: memória, imaginação, pensamento, e principalmente a oralidade” (Barros, Tavares \& Marques, 2018, p. 6). Urge, portanto, a necessidade da reflexão sobre as influências da música no desenvolvimento humano. Com efeito, é indicada uma fundamentação teórica sobre os assuntos temáticos e correlatos, concernentes à relevância da música na aprendizagem da pessoa com deficiência múltipla, argumentando-se também que a atividade musical é um direito de todos, e, uma vez que as pessoas a detêm, elas são susceptíveis de exercê-lo, com ou sem deficiência.

Diante disto, esta pesquisa objetiva investigar a influência da música no desenvolvimento da aprendizagem do aluno com deficiência múltipla, sob o amparo das cantigas populares e no cotidiano infantil. Especificamente, intenta identificar as aquisições no vocabulário, verificar a interação no ambiente escolar e repercussão no contexto familiar.

\section{Metodologia}

Trata-se de uma pesquisa de natureza qualitativa, que trabalha dentro do contexto natural os fatos e informações, sendo o pesquisador o instrumento fundamental entre o ambiente e a situação investigada. Seu procedimento é do tipo estudo de caso, reconhecido pelo aprofundamento do objeto de pesquisa partindo da realidade onde se estabelece. Quanto ao objetivo, se encaixa na pesquisa do tipo exploratória, pois "[...] são úteis para diagnosticar situações, explorar alternativas ou descobrir novas ideias" (Oliveira, 2011, p. 21).

O Estudo de Caso foi realizado em uma escola de ensino patrimonial, em Fortaleza-CE nos anos de 2017 e 2018, com uma criança que estudava pela manhã e, no período da tarde tinha uma vez por semana atendimento educacional especializado (AEE), com fonoaudiólogo, psicopedagogo e terapeuta ocupacional. Inicialmente procedeu-se a busca dos documentos (laudo médico, relatórios e anamnese) para se proceder ao planejamento da pesquisa (Gomes, Poulin \& Figueiredo, 2010). O laudo médico exibia o diagnóstico clínico de Síndrome de Down, Transtorno do Espectro Autista-TEA e baixa visão, pois, ela nasceu com catarata congênita bilateral. 
Diante do exposto constata-se um caso de DM por se tratar de associações de mais de um tipo de deficiência. A participante desta demanda apresentava a Síndrome Down, conhecida como trissomia do cromossomo 21 (Ramos \& Müller, 2020), esta alteração genética prejudica o desenvolvimento do ser humano e define nele algumas características físicas e atraso cognitivo (Brasil, 2012). Também possui o Transtorno do Espectro Autista-TEA, os autores Belisário Filho, Cunha (2010), Louro (2014), Vicari, Rahme (2019), American Psychiatric Association (APA, 2014), Júnior e Moreira (2021), apontam que se caracteriza por um desenvolvimento afetado nos relacionamentos como na interação social e comunicação, além de exibir um repertório limitado de atividades e interesses, e os níveis de manifestações possuem variação em idade e grau de desenvolvimento. Além disso, apresenta a deficiência visual-baixa visão, estas pessoas têm impedimentos de ordem sensorial, com perca total definitiva (cegueira) ou diminuição da acuidade visual com base na escala optométrica entre 6/20 e 6/60, diferindo-se as duas pelo resíduo visual remanescente (Juvêncio, 2017; Salton, Agnol \& Turcatti, 2017).

Os relatórios escolares e anamnese indicaram que a aluna iniciou seus estudos em 2015, aos 9 anos de idade, tinha dificuldade na comunicação, atraso no desenvolvimento, dificuldade na socialização, não demonstrava interesse em participar das atividades pedagógicas. Também atestaram que a aluna apresentava resistência em entrar na sala de aula e ao adentrá-la ficava agachada no canto da sala e apresentava comportamentos estereotipados de mãos, ela só interagia com a professora por meio de gestos simples e expressões faciais, sua linguagem oral se limitava a vocalizações sem intenção comunicativa. Não se locomovia sozinha no espaço escolar e lanchava no corredor da escola pois se recusava ir para o refeitório, ela se jogava no chão e ficava agachava ficava todo o período de intervalo, perto da avó e ao ouvir barulhos tapava os ouvidos com as duas mãos. A aluna gostava de ouvir música e se concentrava com essa atividade, então em 2016 ainda na educação infantil foi indicada para uma intervenção com o objetivo de estimular o desenvolvimento e a aprendizagem, respaldado por Juvêncio (2019).

Foi realizada uma entrevista com a família a fim de sondar as músicas conhecidas pela criança e conhecer a sua rotina. Para Gomes et al. (2016) existe a preeminente necessidade da participação da família e escola visando o desenvolvimento da criança.

[...] a necessidade de centrar um planejamento garantindo uma participação efetiva com a família e a escola para organizar estratégias de modificação de ambientes nos quais a pessoa passa a maior parte do tempo, bem como de aproveitar as atividades que ocorrem no dia, tornando-as significativas em ações, conhecimento e diálogo entre as crianças e seus familiares, e na escola entre os amigos, o professor e os profissionais do contexto escolar (Gomes et al; 2016, p. 140).

De acordo com a entrevista, soube-se que a responsável pela criança era a avó materna, e ela mencionou que a aluna ficava em casa ouvindo música o dia inteiro por meio de um som portátil ou no celular, não tinha amigos e só saia de casa para escola, para o atendimento especializado e a igreja, mas não interagia com as pessoas nem adentrava o templo; quando ouvia barulho desconhecidos ela se jogava no chão e tapava os ouvidos. O repertório que ela ouvia era formado por músicas infantis populares e religiosas.

Em decorrência da grande receptividade da criança à música, com base nesta motivação, decidiu-se desenvolver atividades com as canções que faziam parte do seu contexto familiar, para captar ao máximo seu interesse e atenção. O Trem (Figura 1), na versão cantada de Bia Bedran (1987) era a música mais cantada e repetida pela aluna, por isso foi escolhida para ser a porta de entrada na organização do planejamento das atividades a serem desenvolvidas. Com esteio na canção sob comentário, foi realizado um planejamento de atividades seguindo sugestões descritas por Deckert (2012). Realizou-se a intervenção de musicalização duas vezes por semana na sala de aula com todos os alunos da turma, e o tempo de realização da pesquisa foi de dois anos. Foram trabalhados os conteúdos, a comunicação e oralidade, a interação e o deslocamento utilizando as letras, a melodia e o ritmo. 
Figura 1. Partitura da música O trem Bia Bedran (1997).

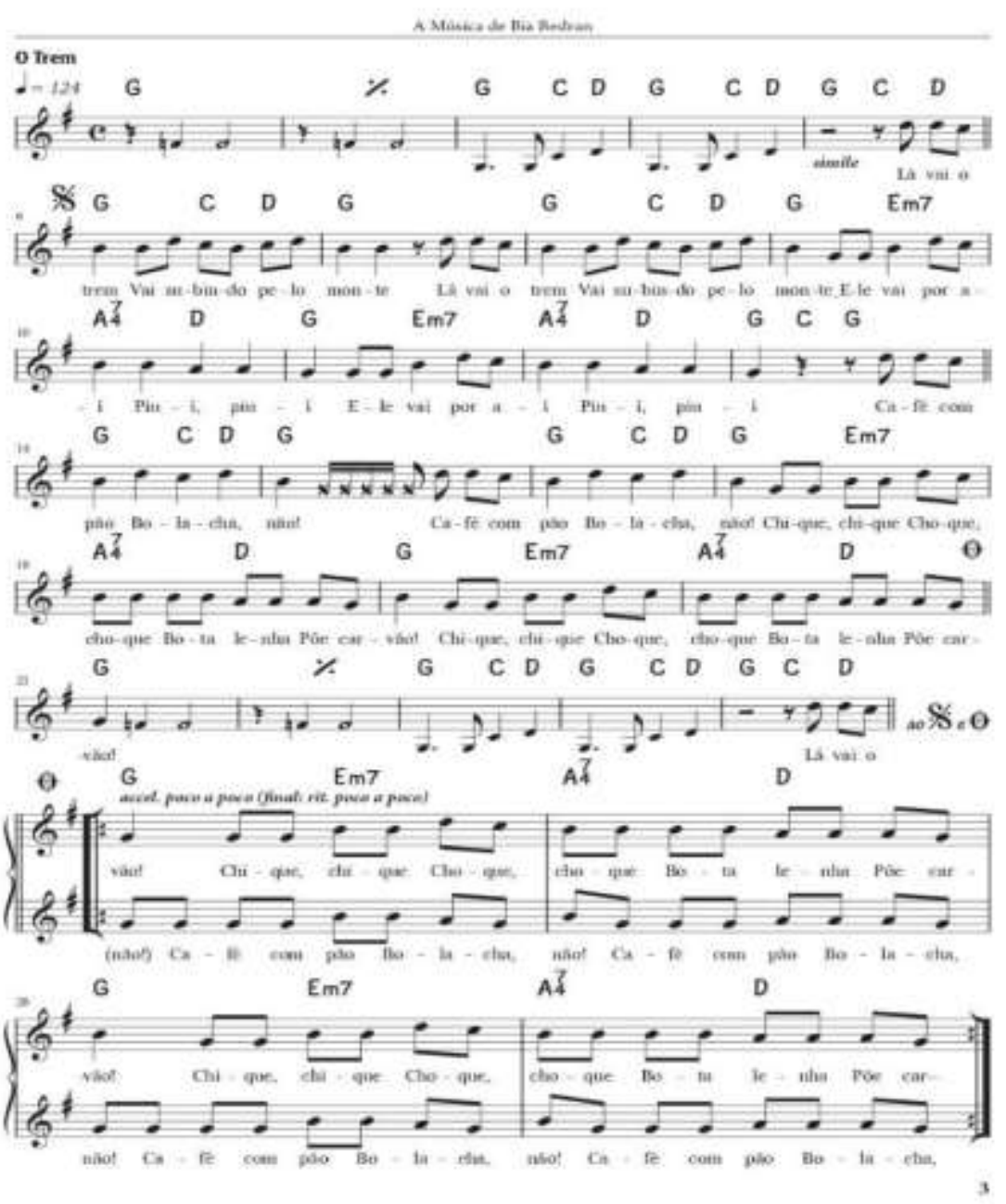

Fonte: Bia Bedran (1997).

Nas aulas práticas de música foram realizadas atividades explorando; sons no corpo, grave, médio e agudo por meio da imitação, ou seja, reproduzindo-os usando as diversas partes do corpo, mãos batendo na cabeça, no rosto, na barriga, nos braços, nas pernas, nos pés; os movimentos corporais seguindo uma sequência rítmica como exemplo: palma, pé, palma ou palma, pé, cabeça, palma, etc. Também os nomes com ritmo, explorando a coordenação do movimento e a expressão verbal e manipulação de instrumentos musicais de bandinha; deslocamento por meio de acompanhamento musical; dinâmica musicais e também foram aplicados exercícios de respiração e de relaxamento, meios efetivos que se empregam para iniciar e concluir uma aula com crianças deficientes, visto que elas, na maioria das vezes, denotam problemas de respiração ou de emissão vocal, sendo esta o elemento em que o som se estabelece e é preciso ter atenção especial a ela, como também ao relaxamento que deverá sempre ocorrer antes do exercício sensorial (Coll, Marchesi \& Palacios, 2007).

Citando os brinquedos de roda, a educadora Brito (2003) descreve as atividades musicais utilizando O trem de ferro como uma das canções mais propagadas no Brasil, tendo distintas variantes, de acordo com a cultura de cada região, e é excelente para ser trabalhado na infância, porque explora conteúdos como os meios de transportes, a ideia de viajar pelo mundo, variações de velocidade, aspectos inerentes ao estudo do som, improvisações e apreciação musical. Portanto, todas as aulas de música desenvolvidas na escola eram finalizadas com um passeio pelo espaço do prédio, onde na brincadeira os alunos eram organizados em fila em forma de trenzinho andando e cantando a música $\mathrm{O}$ Trem, e durante o trajeto eram 
apresentados os espaços da escola e outros membros do corpo docente, que interagiam com os alunos que seguiam, em direção ao refeitório.

E por fim, dando continuidade, também se recorreu ao trabalho com a música O Relógio da Vovó (Figura 2). Com as aplicações dessas músicas infantis, dentre outras, inseridas em um plano de atividades, foram observados progressos no desenvolvimento da comunicação da criança, mas principalmente nas interações sociais.

Figura 2. Partitura O Relógio da Vovó.

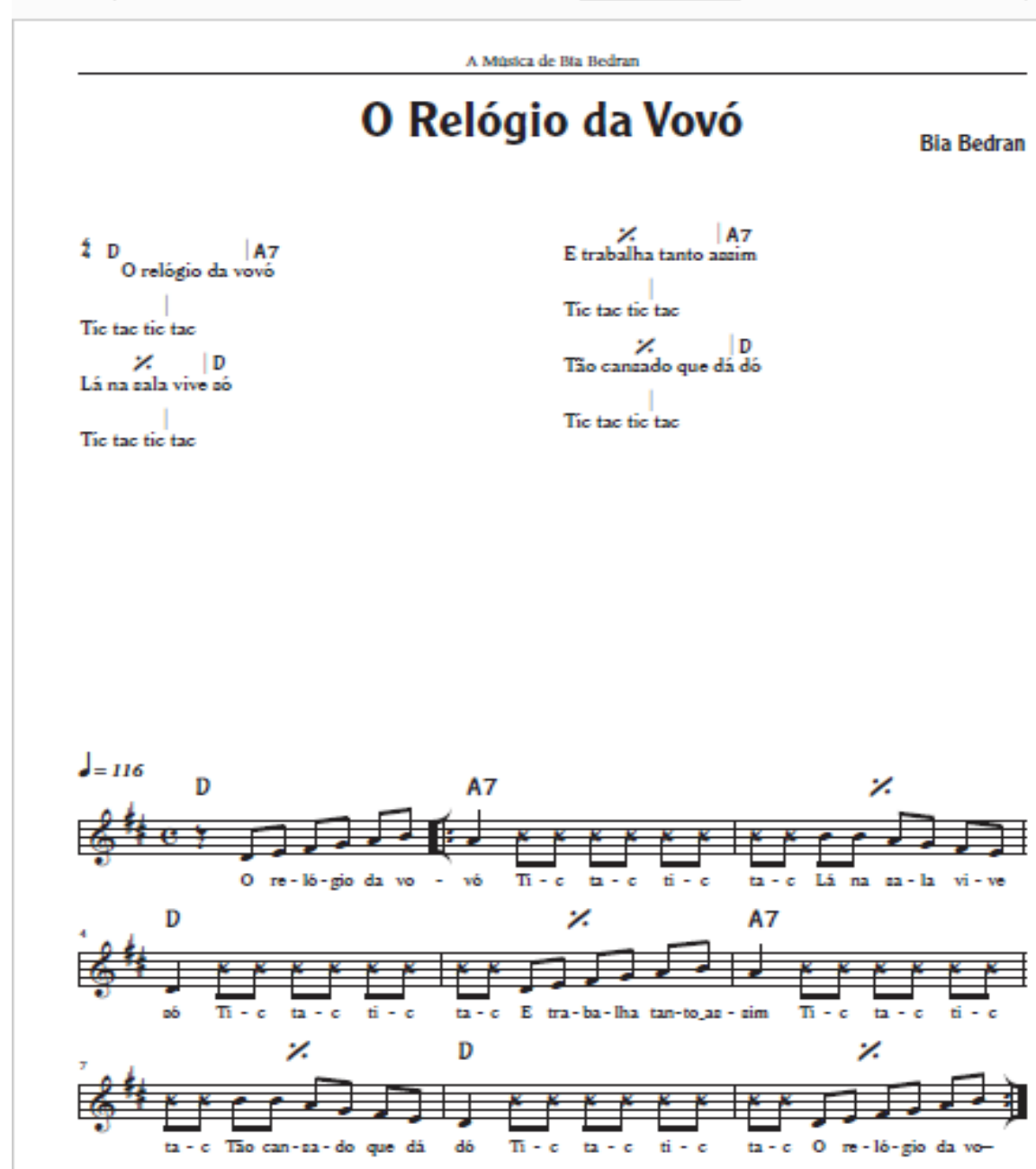

Fonte: Bedran (1997).

\section{Resultados e Discussão}

Nos primeiros meses de aula, a aluna mostrou bastante resistência a qualquer mediação da professora, não aceitava participar do passeio no trenzinho com colegas e professora. Ela só lanchava no corredor da escola por não aceitar o deslocamento até o refeitório e, não adentrava as salas de informática, biblioteca e auditório do estabelecimento. A cada dia exibia modalidades específicas de comunicação, às vezes ficava agressiva ou isolava-se, se jogava no chão e colocava as mãos tampando os ouvidos, emitia vocalizações ou ficava repetindo o nome da música $O$ trem, outras vezes ficava agressiva, contorcia o corpo e empurrava a professora. Esse tipo de conduta apresentada, é expresso por deficientes múltiplos quando eles utilizam-se da comunicação não simbólica para externarem as suas necessidades, neste contexto compete ao mediador conhecer os "sistemas de comunicação" dos DM e assim tornar-se parceiro nesse diálogo (Gomes, et al., 2016). 
$\mathrm{O}$ ato comunicativo é precedido pelo entrosamento entre o mediador e a pessoa com DM, a comunicação tátil, a técnica da antecipação, o objeto de referência e o uso de pistas são indispensáveis no processo de mediação por favorecer um relacionamento de segurança ao deficiente múltiplo, estes recursos ampliam e predizem a comunicação. Em todas as etapas do trabalho realizado, sempre eram informadas à participante as atividades previstas, para que ela as introduzisse na sua rotina diária e, assim, estabelecesse relações com pessoas e coisas de sua convivência (Gomes, et. al., 2016).

A partir do segundo semestre, aos poucos, foi observado o envolvimento da criança nas dinâmicas, ela empolgava-se e participava das atividades e do trenzinho dentro da sala de aula, e demonstrava estar confortável, principalmente devido a se identificar e conhecer a música, mas, quando sentia que o trenzinho estava saindo da sala em direção a outro espaço da escola, denotava insatisfação e desagrado, externando expressões faciais veementes e movimentos intensos. Pode-se destacar que as ações descritas revelam uma intencionalidade comunicativa, ou seja, as pessoas com deficiência múltipla sensorial as utilizam para exprimir vontades e desagrados ao "[...] sorrir, franzir a testa, fazer careta, mostrar surpresa e raiva" (Gomes, et. al., p. 139), cabendo aos professores, pais, cuidadores ou mediadores atribuir sentido a estes sinais naturais para a ampliação de uma comunicação efetiva.

Ao se utilizar ludicamente das melodias, do ritmo, do timbre e das dinâmicas aos poucos, a estudante passou a participar e interagir com as brincadeiras, tendo sido, então, iniciado o deslocamento da sala de aula para outras dependências da escola. Durante as atividades, a aluna marcava o ritmo ao bater palmas e ao caminhar, ia cantando a letra da música e marchando, ao formar a fila para participar do passeio aos espaços da escola, juntamente com os colegas, a professora e outros profissionais, manifestando contentamento (Deckert, 2012), pois, independentemente de o ser humano deter talento musical, deve-se promovê-lo acima de tudo, devendo as atividades nessa área incluir todos os alunos e fazer parte da formação das crianças com deficiência (Brito, 2003).

Uma vez realizadas as séries de repetição nas aulas e de deslocamento no trenzinho durante o período de pesquisa, a criança deste estudo identificou outras pessoas na comunidade, conheceu espaços distintos, como as salas de informática e da biblioteca, auditório e refeitório da escola. A intervenção contribuiu sobremodo, pois a criança passou a utilizar esses locis e ali permanecer para realizar as atividades pedagógicas, havendo, também, conhecido outros componentes da comunidade escolar, além da professora, interagindo com outros elementos reais (coisas) e pessoas da comunidade. Sobre os deslocamentos, a BNCC (Brasil, 2018) esclarece que, nos anos iniciais do Ensino Fundamental (EF), é abordado que os alunos passam por transformações, com vistas a contribuir nas interações com escola e sociedade:

[...] a maior desenvoltura e a maior autonomia nos movimentos e deslocamentos ampliam suas interações com o espaço; a relação com múltiplas linguagens, incluindo os usos sociais da escrita e da matemática, permite a participação no mundo letrado e a construção de novas aprendizagens, na escola e para além dela; a afirmação de sua identidade em relação ao coletivo no qual se inserem resulta em formas mais ativas de se relacionarem com esse coletivo e com as normas que regem as relações entre as pessoas dentro e fora da escola, pelo reconhecimento de suas potencialidades e pelo acolhimento e pela valorização das diferenças (Brasil, 2018, p. 58).

Na atividade comemorativa escolar referente ao Dia das Mães do ano de 2018, depois de vários ensaios, com o apoio da professora e doutros profissionais, a criança adentrou o auditório, subiu ao palco, cantou e dançou uma música para comemorar a data, diante de toda a comunidade escolar. Essa experiência foi o resultado da intervenção feita com a aluna, levando-se em conta o nível de comunicação, que desencadeou um planejamento de atividades, com vistas a possibilitar à criança com deficiência múltipla uma relação de confiança e motivação do seu interesse, com o objetivo de favorecer expressões emocionais e corporais no ambiente escolar (Gomes, et al., 2016).

Um dia, iniciou-se outra música, esta intitulada $\mathrm{O}$ relógio da vovó (Figura 2). Foram feitos exercícios de relaxamento, não havendo a participante expressado resistência à nova melodia. Falou-se a poesia da música, trabalhando entonação, da 
melodia e se fez uso de instrumentos de percussão para marcar o ritmo tic tac, esta canção foi muito bem aceita pela criança. Kebach e Duarte (2012), com pertinência a esta matéria, salientaram a Educação Musical especializada integrada ao currículo geral do aluno com deficiência, de modo a contribuir e estimular o desenvolvimento da percepção, psicomotricidade e ritmo.

Gainza (1988), ao seu turno, acentua que a música contribui para o desenvolvimento, citando os estudos do pedagogo e educador musical belga Edgar Willems, destacando o fato de que cada elemento musical tem relação direta com um aspecto humano, ou seja, o ritmo musical mobiliza o movimento corporal, a melodia movimenta a afetividade e a harmonia estimula o equilíbrio mental. Nessa contextura, entende-se que as atividades com os elementos da música constituem uma fonte para despertar e contribuir para o desenvolvimento das potencialidades humanas.

É importante destacar a música como um preponderante meio de contribuir com a aprendizagem de uma pessoa, seja ela com ou sem deficiência, Louro (2014), postula o argumento de que uma pessoa com deficiência deveria possuir as mesmas oportunidades na educação e aprendizagem musical que uma sem deficiência vislumbra, sendo uma escolha. Por conseguinte, todos têm o direito à educação e à cultura, porque a experiência da Educação Musical trata de elementos importantes para a formação humana, conformados em socialização, ritmo, equilíbrio e outros.

Sobre as atividades desenvolvidas na Educação Musical, Kebach e Duarte (2012, p. 107) explicitam acerca da contribuição da música para o desenvolvimento das habilidades dos alunos.

A aula de música contribui para o desenvolvimento das pessoas com necessidades educacionais especiais por meio do processo de musicalização, oferecendo assim, atividades que ampliam a percepção auditiva e rítmica. As atividades de musicalização devem despertar o interesse pela exploração sonora, propiciando condições para a escuta ativa, improvisação e criação musical. Nestes ambientes de Educação Musical, os sujeitos são desafiados a relacionarem ações exercidas, através da produção criativa, em que exploram sons e objetos sonoros ou instrumentos musicais, com a voz e movimentos corporais e, ao mesmo tempo, coordenarem essas descobertas com a produção dos colegas (Kebach \& Duarte, 2012, p. 107).

Ao final de dois anos com a intervenção a aluna já estava familiarizada com a escola, chegava de bom humor sabia falar o nome de todos os colegas da turma e, já conseguia se aproximar deles e tocá-los nas mãos. Ao mesmo tempo conseguia se concentrar nas atividades pedagógicas sentada numa cadeira, na mesa com outros alunos realizava atividades de montagem, encaixe, alinhavo e pintura com tinta guache. Gostava de dançar, e tinha grande interesse em histórias musicadas e canções, tinha facilidade na memorização de letras, ritmo e melodias de músicas, mesmo possuindo uma comunicação prejudicada no seu desenvolvimento ela cantava e possuía um repertório específico.

\section{Conclusão}

Por meio das mediações com a música aos poucos, a aluna foi acrescentando ao seu repertório outras músicas e, a igual tempo, adicionou novas palavras ao seu vocabulário. Foi observada melhora significativa na sua capacidade de interação e relacionamento com as pessoas no ambiente escolar. Agora, com ou sem música, a menina-alvo desta demanda obtém sucesso em se deslocar até o refeitório, com ajuda da professora ou de outros profissionais da escola. No contexto familiar houve repercussão do trabalho realizado, os familiares atestam que a criança está mais comunicativa, e chega em casa pronunciando palavras que não conhecia, aprendidas na escola, uma vez que, mesmo ao se encontrar com pessoas desconhecidas de seu convívio, ela lhes demonstra carinho e receptividade.

A música no contexto do ensino para crianças com deficiência oportunizou uma educação direcionada para a participação, desenvolvimento da autonomia e conhecimento, estas situações viabilizam o avanço integral dos educandos. Com a investigação realizada, restou mais uma vez comprovado o fato de que a música é uma linguagem ocorrente no dia a dia das pessoas, ou seja, faz parte da cultura e encontra-se nas diversas situações da vida. É um excelente meio de contribuir com a 
aprendizagem, independentemente de quem estiver sob tal circunstância mostrar-se com ou sem deficiência. Na contextura da educação de pessoas com deficiência, impõe-se a adoção de metodologias específicas, visando a atender às demandas individuais do aluno, conforme suas dificuldades intelectuais.

É prazeroso, do ponto de vista das autoras do ensaio, perceber que a experiência com a música efetivou a inclusão social da aluna no contexto escolar, porquanto, para crianças com deficiências, saber conviver em grupo e interagir com ele constitui um momento de relevo no seu decurso de aprendizagem, uma vez que esses infantes, em seu cotidiano, costumam experimentar momentos de isolamento.

Reitera-se a verdade conforme a qual a música, por intermédio de um ensino contextualizado, concorre para o desenvolvimento da aprendizagem. É de todo favorável, por conseguinte, a vivência dessa linguagem na ambiência escolar, uma vez que a música é atemporal, perpassa o tempo e produz reflexão, alegria e inclusão. Com efeito, é indicada uma fundamentação teórica sobre os assuntos temáticos e correlatos, concernentes à relevância da música na aprendizagem da pessoa com deficiência, argumentando-se também que a atividade musical é um direito de todos, e, uma vez que as pessoas o detêm elas são susceptíveis de exercê-lo, com ou sem deficiência.

O tema estudado não está esgotado, esperamos que os resultados contribuam como fontes de pesquisa para futuras discussões, reflexões e práticas nas diversas áreas de conhecimento e, por meio destas, outras ferramentas metodológicas sejam aplicadas para possibilitar o desenvolvimento e a melhoria das pessoas com deficiência em sua vida diária.

\section{Referências}

Almeida, I. C. L. (2003). A música na escola de ensino fundamental em fortaleza: reflexões sobre a prática docente. (Monografia de Graduação). Universidade Estadual do Ceará.

American Psychiatric Association. (2014). DSM-5: Manual diagnóstico e estatístico de transtornos mentais. Artmed Editora

Barros, R. M. R., Tavares, L. S. P., \& Marques, L. C. (2018). A importância da música para o ensino-aprendizagem na educação infantil: reflexões à luz da psicologia histórico-cultural. In Anais do Colóquio Luso-Brasileiro de Educação-COLBEDUCA, Braga e Paredes de Coura, Portugal.

Bedran, B. M. O Relógio da vovó. A música de Bia Bedran. 1 partitura. https://drive.google.com/file/d/1JRzE8FLcGw32cAQqJnzUbndi8p7 $\mathrm{S} 7 \mathrm{WTQ} /$ view?usp=sharing

Bedran, B. M. O Trem. A música de Bia Bedran. 1 partitura. https://drive.google.com/file/d/1JRzE8FLcGw32cAQqJnzUbndi8p7S7WTQ/view?usp=sharing

Belisário, J. F., \& Cunha. P. (2010). A educação especial na perspectiva inclusiva escolar: transtornos globais do desenvolvimento. Brasília: Secretaria de Educação Especial do Ministério da Educação

Bosco, I. C. M. G., Mesquita, S. R. S. H. \& Maia, S. R. (2010). A Educação Especial na Perspectiva da Inclusão Escolar: surdocegueira e deficiência múltipla. In Bosco, I. C. M. G., A educação especial na perspectiva da inclusão escolar: surdocegueira e deficiência múltipla, Brasília: Ministério da Educação, Secretaria de Educação Especial

Brandão J. (2011). Vivências e Convivências com a Deficiência Visual: relatos e práticas de profissionais. Scortecci

Brasil. (2008). Lei n 11.769, de 18 de agosto. de 2008. Altera a Lei no 9.394, de 20 de dezembro de 1996, Lei de Diretrizes e Bases da Educação, para dispor sobre a obrigatoriedade do ensino da música na educação básica. https://legislacao.presidencia.gov.br/atos/?tipo=LEI\&numer o=11769\&ano=2008\&ato =adcoXVE5 UNRpWT2bd\#: :text=Lei\%20n\%C2\%BA\%2011.769\%20de\%2018\%20de\%20agosto\%20de\%202008,-Data\%20de\%20assinatura\&text $=$ ALTERA $\%$ 20A\%20LEI\%20N\%C2\%B0,DA\%20M\%C3\%9ASICA\%20NA\%20EDUCA\%C3\%87\%C3\%830\%20B\%C3\%81SICA

Brasil. (2012). Diretrizes de atenção à pessoa com Síndrome de Down. Brasília: Ministério da Saúde. Secretaria de Atenção à Saúde

Brasil. (2012). Lei $n^{o}$ 12.764, de 27 de dezembro de 2012. Institui a Política Nacional de Proteção dos Direitos da Pessoa com Transtorno do Espectro Autista, Recuperado de http://www.planalto.gov.br/ccivil_03/_ato2011-2014/2012/lei/112764.htm

Brasil. (2015). Lei Brasileira de Inclusão da Pessoa com Deficiência no 13.146, de 6 de julho de 2015 (Estatuto da Pessoa com Deficiência). Diário Oficial da União, Brasília, DF. Recuperado de http://www.planalto.gov.br/ccivil_03/_ato2015-2018/2015/lei/113146.htm

Brasil. (1998). Referencial curricular nacional para educação infantil. Ministério da Educação e do Desporto. Secretaria de Educação Fundamental. Brasília: $\mathrm{MEC} / \mathrm{SEF}$

Brasil. M. D. E. (2018). Base nacional comum curricular. Brasília-DF: MEC, Secretaria de Educação Básica. Ministério da Educação. (2018. http://basenacionalcomum.mec.gov.br/images/BNCC_EI_EF_110518_versaofinal_site.pdf 
Research, Society and Development, v. 10, n. 11, e542101119830, 2021

(CC BY 4.0) | ISSN 2525-3409 | DOI: http://dx.doi.org/10.33448/rsd-v10i11.19830

Brito, T. A. D. (2003). Música na educação infantil. Peirópolis

Coll, C., Marchesi, Á., \& Palacios, J. (2007). Desenvolvimento Psicológico e Educação: transtornos de desenvolvimento e necessidades educativas especiais São Paulo: Artmed

Deckert, M. (2012). Educação Musical: da teoria à prática na sala de aula. Moderna

Felício, F. A. S., Junior, M. O. S. \& Rodrigues, V. (2019). Brinquedos educativos associados À contação de histórias aplicados a uma criança com deficiência múltipla. Revista Brasileira de Educação Especial, 25, 67-84. https://doi.org/10.1590/S1413-65382519000100005

Gainza, V. (1988). Estudos de Psicopedagogia Musical. Summus

Ivic, I. (2010). Lev Semionovich Vygotsky. Massangana

Godói, A. M. (2006). Educação infantil: saberes e práticas da inclusão: dificuldades acentuadas de aprendizagem: deficiência múltipla. Brasília: MEC, Secretaria de Educação Especial

Gomes, A. L. L. V., Poulin, J. R. \& Figueiredo, R. V. (2010). A Educação Especial na Perspectiva da Inclusão Escolar: o atendimento educacional especializado para alunos com deficiência intelectual. Fortaleza: Universidade Federal do Ceará

Gomes, R. V. B., Figueiredo, R. V. D., Silveira, S. M. P., \& Faccioli, A. M. (2016). Políticas de inclusão escolar e estratégias pedagógicas no atendimento educacional especializado. Universidade Federal do Ceará

Júnior, D. S. S. \& Moreira, P. L. (2021). Transtorno do Espectro Autista e as tecnologias educacionais digitais no cenário das pesquisas brasileiras: um Mapeamento Sistemático da Literatura. Research, Society and Development, 10(10), e119101018328-e119101018328. http://dx.doi.org/10.33448/rsdv10i10.18328

Juvêncio, V. L. P. \& Trompieri, F. N. (2017). Acessibilidade de pessoas com deficiência visual: recursos que ajudam muito além das palavras. Fortaleza: Imprensa Universitária

Juvêncio, V. L. P. (2019). O uso das tecnologias da informação e comunicação (tics) na avaliação da aprendizagem de alunos cegos nas escolas especiais em Fortaleza-CE. (Tese doutorado). Universidade Federal do Ceará, Fortaleza-CE

Kebach, P., \& Duarte, R. (2012). Educação musical e educação especial: processos de inclusão no sistema regular de ensino. Textos e Debates, 2(15), 98-111. Recuperado de https://revista.ufrr.br/textosedebates/article/viewFile/751/651

Lima, M. S. C. B. M. (2014). Vygotsky e a teoria histórico-cultural: análise da inclusão escolar de deficientes intelectuais. Revista Labor, (12), 59-77. Recuperado de http://repositorio.ufc.br/handle/riufc/23485

Louro, V. (2014). Ações pedagógicas para inclusão de aluno com transtorno do espectro autista numa escola de música de São Paulo: relato de caso. Revista Educação, Artes e Inclusão, 10(2), 138-157. Recuperado de https://www.revistas.udesc.br/index.php/arteinclusao/article/view/5155

Salton, B. P., Agnol, A. D. \& Turcatti, A. (2017). Manual de Acessibilidade em Documentos Digitais. Bento Gonçalves: Instituto Federal de Educação, Ciência e Tecnologia

Oliveira, M. K. (1997). Vygotsky: aprendizado e desenvolvimento, um processo sócio histórico. Scipione

Oliveira, M. F. (2011). Metodologia científica: um manual para a realização de pesquisas em Administração. Catalão: UFG

Penna, M. (2011). A função dos métodos e o papel do professor: em questão, como ensinar música: In Mateiro, T. Ilari B., Pedagogias em educação musical. Curitiba: Ibpex

Ramos, B. B., \& Müller, A. B. (2020). Marcos motores e sociais de crianças com síndrome de down na estimulação precoce. Revista Interdisciplinar Ciências Médicas, 4(1), 37-43. Recuperado de http://revista.fcmmg.br/ojs/index.php/ricm/article/view/290/88

Souza, J. (2009). Aprender e ensinar música no cotidiano. Sulina

Vicari, L. P. L. \& Rahme, M. M. F. (2019). Escolarização de alunos com TEA: práticas educativas em uma rede pública de ensino. Revista Educação Especial, 33(0). .org/10.5902/1984686X43296 